\title{
O TRABALHO POLICIAL: RESULTADO DE UM LEVANTAMENTO DE DADOS EM UMA DELEGACIA ESPECIALIZADA DE PROTECÇÃO AO IDOSO
}

\section{THE POLICIMEN WORK: RESULTS FROM A SURVEY AT A SPECIALIZED DELEGACY OF PROTECTION OF THE ELDER}

\author{
Paulo Guilherme Santos Chaves* \\ Patrícia Lu fza Costa** \\ Tânia Maria Oliveira Alves***
}

Chaves PGS, Costa PL, Alves TMO. O trabalho policial: resultado de um levantamento de dados em uma Delegacia Especializada de Proteção ao idoso. Rev Bras Cresc Desenv Hum 2004;14(2): $35-43$.

\begin{abstract}
Resumo: A Delegacia Especializada de Proteção ao Idoso-DEPI/MG foi criada em 1997 com o propósito de atender ao idoso vítima de maus-tratos. Trata-se de uma unidade policial especializada devido ao seu caráter de atendimento direcionado a um público específico. Infelizmente, embora na vanguarda - foi a segunda unidade nesse porte, criada no Brasil - os policiais designados para atuarem nessa Delegacia não fpram submetidos a algum tipo de capacitação, ou mesmo treinamento. Desde meados de 2000, iniciou-se um trabalho de levantamento de dados nessa Delegacia Especializada de Proteção ao Idoso-DEPItMG, objetivando observar a dinâmica interna e, futuramente indicar possíveis mudanças organizacionais e intervenções. A equipe de pesquisadores, preocupada com os públicos externo e interno, demandou o levantamento sobre a saúde mental dos trabalhadores da polícia civil na Delegacia Especializada de Proteção ao Idoso-DEPI/MG. Esse artigo apresenta o resultado desse levantamento de dados que foi primeiramente aplicado num período inicial de mudanças internas na Delegacia Especializada de Proteção ao Idoso-DEPI/MG e, um ano depois, numa fase de gestão transacional.
\end{abstract}

Palavras-chaves: Saúde mental. Polícia Civil. Idoso. Violência contra o idoso.

\section{INTRODUÇÃO}

Vanagunas ${ }^{1}$, ao considerar a polícia como um serviço social, registrou a estatística de que um quinto das solicitações de serviço policial se refere a eventos relacionados a crimes, no capítulo que trata sobre o planejamento dos serviços sociais policiais urbanos. Dessa forma, tem-se que os problemas que indiretamente envolvam crimes são os mais freqüentes e, portanto, os mais importantes. As solicitações de serviços à polícia, ainda segundoVanagunas, mesmo não relacionadas a crimes, são as que envolvem conflito, bas- tante carregadas emocionalmente, e solucioná-las "requer perícia e controle do temperamento por parte dos policiais, exigências bem diversas daquelas requeridas para lidar com a maioria dos incidentes relacionados a crimes”1 (p. 47)

Considerando essa avaliação feita por Vanagunas ${ }^{1}$ ao observar a polícia norte-americana, e cientes do escasso número de pesquisas voltadas para esse campo no Brasil, pensou-se em avaliar o trabalho realizado por uma unidade policial denominada 'especializada' - pelo caráter de seu atendimento - e, por conseguinte, observar a sua dinâmica interna, determinando em con-

\footnotetext{
* Fisioterapeuta. Especialista em Geriatria e Gerontologia. Responsável técnico-científico pelo Curso de Gerontologia aplicada ao Agente Policial Civil/SENASP. Professor da PUCMINAS-ACADEPOL/MG.

** Professor do Curso de Especialização em Criminologia, da PUCMINAS-ACADEPOL/MG. Doutora em Química Analítica. Pertence ao quadro da Polícia Civil de Minas Gerais. Atua na Divisão Psicopedagógica da ACADEPOL/MG.

*** Psicóloga, pós-graduada em Psicologia Organizacional e do Trabalho. Coordenadora do Setor de Psicologia e professora da ACADEPOL/MG. Rua Oscar Negrão de Lima, 200 - sala 302 - Nova Gameleira - Belo Horizonte. andrealu.bh@terra.com.br
} 
junto com os seus atores, intervenções para possíveis mudanças organizacionais se os resultados dos levantamentos assim demandassem. Escolheu-se a Delegacia Especialida de Proteção ao Idoso - DEPI/MG, primeiro, porque é uma das únicas no Brasil (há três outras: em São Paulo, Rio de Janeiro e Rio Grande do Sul), muito embora com características bem distintas da existente em Belo Horizonte, capital do Estado de Minas Gerais. Segundo, porque ela atende a uma população que, na época, meados de 2000, não possuía uma legislação específica que a salvaguardasse dos delitos criminais sofridos. E, por último, porque ela atua como serviço policial tanto quanto como uma "polícia como um serviço social."1 (p. 47)

O ano de 2000 foi, na verdade, um ano profícuo no que concerne aos levantamentos de dados sobre o trabalho que as forças policiais estaduais, militar e civil, realizavam. Foi o ano de implementação do Plano Nacional de Segurança Pública do Ministério da Justiça² ${ }^{2}$ (2001), em que se iniciou o processo de descentralização de recursos do Governo Federal para, em conjunto com os Estados, reduzir, em um curto espaço de tempo, os alarmantes índices de criminalidade que assolavam o país. Na tentativa de fazer frente à crescente e preocupante onda de criminalidade, alimentada por diversos fatores, dentre os quais destacavam-se os de ordem social e econômica, os Estados enviaram propostas de Planos Estaduais de Segurança Pública ao Ministério da Justiça. As demandas eram enormes e, sobretudo, estruturais. Como o objetivo do plano de ações do Governo Federal era o de aperfeiçoar o sistema de segurança pública brasileiro, por meio de propostas que integrassem as políticas de segurança, políticas sociais e ações comunitárias, de forma a reprimir e prevenir o crime e reduzir a impunidade, aumentando a segurança e a tranqüilidade do cidadão brasileiro, em junho de 2000, as coordenações dos trabalhos de pesquisa realizadas na DEPV/ MG demandaram ao Setor de Psicologia da Academia de Polícia Civil de Minas GeraisACADEPOL, um levantamento sobre a saúde dos trabalhadores da Polícia Civil de Minas Gerais, especificamente, dos servidores que atuavam na Delegacia Especializada de Proteção ao Idoso- DEPI/MG. Observa-se, nessa passagem histórica, a ratificação de alguns dos resultados obtidas por Monjardet ${ }^{3}$, sobre os trabalhos executados pelas polícias francesa e norte-americana, quando identificou que o chamado "poder" que pressiona a ação policial diante de conflitos sociais intensos é, por sua vez, pressionado pela polícia nas suas reivindicações materiais. A po- lícia como instituição é uma ferramenta nas mãos da autoridade política para empregar a força, quando esta se revela necessária para fazer aplicar ou respeitar a lei.

De certa forma, compreende-se a criação de Unidades Policiais Especializadas, pelo menos no tocante ao Estado de Minas Gerais, e cita-se como exemplo a própria DEPI/MG, como uma forma de atender a uma demanda política, não compartilhada com policiais que atuam no atendimento ao público a que se destina; afinal, eles não são preparados para prestar esse tipo de serviço, diferenciado, mais voltado para o campo social.

Desse modo, os primeiros dados obtidos pelos pesquisadores no processo de observação da dinâmica interna na DEPI/MG indicavam a necessidade de se elaborar um curso que pudesse, a partir de uma abordagem transdisciplinar, fornecer conhecimentos básicos na área de gerontologia e comportamento, nos níveis morfológicos, clínicos, psicológicos, fisioterapêuticos, para a capacitação de agentes de polícia. Esse curso serviria como um indicador quanto aos valores sociais básicos relevantes, conforme Menke et al.transdisciplinar, fornecer conhecimentos básicos na área de gerontologia e comportamento, nos níveis morfológicos, clínicos, psicológicos, fisioterapêuticos, para a capacitação de agentes de polícia. Esse curso serviria como um indicador quanto aos valores sociais básicos relevantes, conforme Menke et al. ${ }^{4}$

O Setor de Psicologia da ACADEPOL havia realizado esse mesmo levantamento na Corregedoria-Geral da Polícia Civil e no Departamento Estado de Operações Especiais DEOESP, assim como nos discentes de alguns cursos realizados pela própria Academia de Polícia Civil, tais como: Curso de Aperfeiçoamento Policial; Curso Vida Nova; Curso de Chefia Policial. O objetivo desse levantamento foi pesquisar mais detalhadamente a saúde mental dos servidores policiais de modo a favorecer uma possível mudança nos processos produtivos e na construção de relações mais saudáveis de trabalho.

O cotidiano do trabalho tem estreita relação e reflexo no interior das pessoas, ou sej a, em seu aparelho psíquico. Portanto, fazia-se necessário obter um maior conhecimento a respeito de dados gerais dos policiais da DEPI/MG, de questões concernentes à estrutura e organização do trabalho, das atividades exercidas fora do ambiente do trabalho, dentre outros aspectos. Sem o conhecimento da atividade laboral e de sua dinâmica, tornava-se impossível compreender as vivências subjetivas e intersubjetivas que baseiam a estrutura e o comportamento do policial. Mediante um diagnóstico, poder-se-ia propor alternativas e/ ou 
ações para maximizar a melhoria das relações interpessoais, a motivação, a produtividade, dentre outras ações de intervenção.

Apenas em novembro de 2002 conseguiuse viabilizar condições financeiras, junto à Secretaria Nacional de Segurança Pública - SENASP, para que o Curso de Gerontologia Aplicada aos Agentes Policiais Civis lotados na DFPT/MG se realizasse e portanto, pudesse ser efetuado o levantamento sobre a saúde mental do policial que atuava naquela Unidade Policial.

Pensou-se, em princípio, na execução tanto do projeto do curso, quanto do levantamento sobre a questão da saúde mental, in loco; porém, observando-se as condições das instalações físicas da Unidade Policial e, em consenso com a Chefia Imediata da DEPI/MG, viu-se a inviabilidade desse procedimento. Como o processo de avaliação da dinâmica interna nessa Unidade Policial encontrava-se em franca expansão, decidiu-se, mais uma vez em conjunto, dividir os funcionários lotados na DEPI/MG em duas turmas. A primeira turma submeter-se-ia ao curso e ao levantamento sobre saúde mental no ano de 2002 e a segunda, em 2003. A Chefia Imediata da Unidade Policial responsabilizar-se-ia pela seleção dos servidores que participariam da primeira turma, considerando-se, prioritariamente, a necessidade de se manter os serviços na Unidade Policial, que durante 10 (dez) dias - a carga horária do curso era de 40 (quarenta) horasaula, distribuídas no turno da tarde e realizado no campus da ACADEPOL - a equipe da Unidade Policial se manteria reduzida.

Quanto à segunda turma, a indicação concretizar-se-ia somente no ano de 2003, uma vez que já se previa algumas mudanças de pessoal, diante da favorabilidade das alterações comportamentais percebidas, resultantes das pequenas intervenções indicadas e acatadas pelos servidores da DEPI/MG, complementadas até a realização da primeira turma.

Devido a uma grande resistência quanto às mudanças estruturais e procedimentais que devem ser implantadas, os pesquisadores optaram por utilizar a estratégia de sinalizar aos policiais as necessidades de alterações comportamentais de modo paulatino, apresentando-lhes os resultados dos trabalhos e dos levantamentos efetuados. Embora esse percurso seja lento e árduo, conquistando-se a cumplicidade e a credibilidade dos atores que atuam nesse cenário, poder-se-á obter o auxílio necessário à implantação de fluxogramas consistentes, com a perspectiva de obtenção de resultados mais próximos à realidade do trabalho policial.

\section{MÉTODOS}

Utilizou-se um questionário, elaborado pela Profa. Dra. Mari a El izabeth Lima Antunes, da Faculdade de Filosofia e Ciências Humanas FAFICH, da Universidade Federal de Minas Gerais - UFMG, contendo 92 perguntas agrupadas em quatro estágios . O questionário independe de identificação, sendo livre a sua opção de preenchimento por parte do entrevistado.

O primeiro estágio do questionário aborda os dados gerais dos policiais e foram divididos em seis sub-itens: sexo; setor onde trabalha; posto de trabalho atual; tempo de serviço na Polícia Civil; tempo que trabalha na área atual; escolaridade.

O segundo investiga as questões gerais sobre o trabalho e as 31 questões levantadas foram agrupadas em seis sub-itens, a saber: horário de trabalho; salário; ergonomia; recursos materiais e acidentes de trabalho; autoavaliação/ motivação; dinâmica organizacional.

O terceiro estágio aborda o estado geral de saúde dos servidores e finalmente, no quarto avalia-se as "questões gerais sobre as atividades exercidas fora do ambiente do trabalho".

O levantamento dos dados foi feito somando-se o total dos resultados apurados em cada resposta, totalizando o número de servidores que responderam à pesquisa.

O questionário sobre a saúde dos trabalhadores da Delegacia Especializada de Proteção ao Idoso - DEPI/MG foi aplicado em 10 de novembro de 2003. Como ocorrera em 2002, reservouse duas horas-aula, de $50 \mathrm{~min}$. cada, dentro da grade curricular do Curso de Gerontologia aplicada aos Agentes Policiais Civis para a aplicação do questionário aos servidores da DEPI/MG, que freqüentaram ao curso como discentes.

A coordenação do setor de Psicologia da ACADEPOL foi quem usou os levantamentos nos anos de 2002 e 2003. Mesmo sabendo que os discentes estavam conscientes dos trabalhos de pesquisas que vinham sendo realizados na DEPI/MG, a equipe de profissionais, pesquisadores + coordenação, teve o cuidado de dirimir todas as possíveis dúvidas que pudessem surgir no decorrer do preenchimento do questionário. Utilizou-se, então, da seguinte didática:

I. Optou-se por aulas geminadas; dessa forma, o primeiro tempo foi utilizado para uma aula expositiva. Nesse momento, fez-se a apresentação do questionário ao público-alvo, pontuando-se e esclarecendo-se as seguintes indagações:

a) Porque a DEPI/MG foi escolhida para a realização deste levantamento sobre a saúde dos trabalhadores da Polícia Civil? 
b) Outras unidades da Polícia Civil submeteram-se aesse questionário? Quais?

c) Esse instrumento de medida, denominado questionário, é composto por quantas perguntas no total. Elas são subdivididas de que maneira?

d) É obrigatória a participação de todos?

e) É preciso se identificar?

f) Qual é o objetivo desse questionário?

2.Em um segundo momento, aplicou-se o questionário, recolhendo o ao término da aula.

\section{Análise comparativa entre os resultados de 2002 e 2003}

O primeiro levantamento sobre a saúde dos trabalhadores da DEPI/MG foi realizado em novembro de 2002. Na época foram aplicados 13 questionários, número total de alunos que participaram do Curso de Gerontologia aplicada aos Agentes Policiais Civis.

Um ano depois, o módulo II do mesmo curso permitiu que o restante dos servidores que atuam na DEPI/MG, ou seja, 10 alunos, pudessem responder ao mesmo questionário que foi aplicado aos seus colegas no ano de 2002.

Foi realizada uma comparação entre as duas turmas, destacando-se os pontos em comum bem como as divergências.

Na turma de 2002, houve uma diversidade de carreiras estritamente policiais atuando como discentes no curso: Delegado de Polícia; Escrivão de Polícia, Detetive, Estagiário (Psicólogo) e Funcionário Administrativo (Técnico em Enfermagem), divergindo da $2^{\mathrm{a}}$ turma em que todos pertenciam à carreira de Detetive. A $1^{\mathrm{a}}$ turma possuía maior número de integrantes pertencentes ao sexo masculino, $60 \%$.

A média de tempo de serviço estritamente policial seguiu a mesma escala, ou seja, entre 07 e 08 anos; porém, a turma de alunos do ano de 2002 atuava na DEPI/MG há mais tempo, em média 02 anos. Em 2003, a média foi de 01 ano de prestação de serviços na DEPI/MG.

O nível de escolaridade manteve o mesmo resultado, ou seja, $60 \%$ possuía nível médio de escolaridade e o restante, nível superior.

As duas turmas apresentaram um índice percentual idêntico quanto ao tópico horário integral, sendo que $40 \%$ faziam o horário noturno de trabalho.

O salário, em ambas as turmas, foi avaliado como abaixo do que realizavam profissionalmente, levando-se em conta a periculosidade e a responsabilidade inerente à função policial.

De igual modo, o espaço físico foi citado como insatisfatório pelas duas turmas. Realmen- te, dos levantamentos efetuados pelos pesquisadores, um deles dirigido exclusivamente à questão da ergonomia na DEPI/MG. Observou-se, à época, que embora tendo sido alertada sobre a existência da lei $n^{\circ}$ 11.666/94 que determina as regras, de acordo com a Associação Brasileira de Normas Técnicas ABNT, para os locais de atendimento ao público idoso e deficiente físico quanto aos tópicos "circulações horizontais" e "rampas", os dirigentes da DEPI/MG realizaram algumas mudanças arquitetônicas que facilitaram o acesso do público externo à Unidade Policial, preocupando-se muito pouco com as condições de atuação do público interno, mesmo sabendo que o local não é propício para o atendimento dessa minoria social.

As duas turmas consideraram o sistema informatizado como falho impedindo sua plena utilização. Na verdade, pôde-se notar, in loco pelos pesquisadores, a existência de um número reduzido de computadores para o registro de dados, nenhum deles ligados em rede e, todos, três ao todo, contendo recursos eletrônicos insatisfatórios, sendo que um dos três computadores foi conseguido como doação pelos pesquisadores.

O descaso com o registro de dados na polícia pode ser considerado cultural. Poder-se-ia explicar esse fato considerando-se três abordagens:

a) As fontes de opacidade e inércia, mencionadas por Monjardet ${ }^{3}$, que auxiliam na cobertura de algumas ações policiais e que geram, automaticamente, a organização burocrática da não-responsabilidade.

b) A quase paranóica desconfiança policial, segundo Bittner ${ }^{6}$. Há, na realidade, uma forte aversão da polícia em ter seus trabalhos observados por pessoas de fora da polícia e em reconhecer qualquer problema interno. Isso não é prerrogativa exclusiva da polícia brasileira, ou mineira, e sim, de toda e qualquer organização policial no mundo. Para o policial, uma vez mantida a informação em suporte eletrônico, "qualquer um" poderá acoessar os dados e, portanto, utilizar essa informação como forma de pressão, sabotagens, entre outros acontecimentos.

c) Mais uma vez concordando com Bittner ${ }^{6}$, o baixo valor, a baixa importância e o desconhecimento da complexidade do trabalho policial rotineiro e cotidiano pelos próprios policiais.

Além destes, deve-se incluir dois outros

1) A ineficácia e a ineficiência dos gestores da segurança pública, em rei- 
vindicar suas necessidades materiais pautadas em planejamentos orçamentários, financeiros e metas.

2) A crença por parte dos policiais de que o papel da polícia concentra-se, exclusivamente, no policiamento investigativo e criminal, sendo, portanto, de menor valia e não de polícia, o trabalho de registro das operações policiais.

Os acidentes de trabalho também são pouco freqüentes, embora, os equipamentos de proteção individual sejam apontados como obsoletos e ruins.

Na auto-avaliação e/ou motivação, houve consenso entre as duas turmas no que se refere ao medo de errar. Eles demonstraram esse medo pelo fato de sofrerem conseqüências, não só na queda da qualidade do trabalho como na criação de um clima ruim entre os colegas e também com a chefia. Em ambos os casos, apesar das dificuldades apontadas, eles estavam satisfeitos exercendo as funções de profissionais de segurança pública.

Observou-se que na turma 1 , a de 2002, quanto à dinâmica organizacional, os discentes apontavam a necessidade de se alterar a rotina de trabalho; já na turma 2, a de 2003, viu-se que houve alterações de rotinas, embora simples, mas que resultaram numa melhoria da qualidade de vida dos funcionários na DEPI/M:G. Observando o fluxo de pessoal e documentos na DEPI/MG durante os anos de 2000 a 2002, Chaves e Costa ${ }^{7}$ desenvolveram uma metodologia de trabalho que priorizou a organização e métodos, denominada Mapa de Instrução. Esse documento norteia todas as ações dos policiais, servidores administrativos e estagiários na DEPI/MG. Nele pode-se encontrar todos os modelos dos formulários criados para coleta de dados, legislações pertinentes ao tema idoso, organograma e fluxograma das ações sob a responsabilidade da DEPI/MG. Assim, passou-se a caracterizar o atendimento da Delegacia como policial e não, como outrora, terapêutico. A influência dos servidores administrativos e estagiários na rotina dos servidores Iminentemente policiais causava um grande desconforto aos policiais que preferiam omitir-se das ações quanto à escuta adequada da vítima e ao registro de informações relevantes nos documentos emitidos pela delegacia por não saberem qual o papel que cada ator desempenhava na DEPI/ MG. Nota-se, atualmente, uma maior preocupação com a coleta de dados, assim como uma maior conscientização da importância desses dados. Essa observação se reflete no alto índice de 'ordens de serviços’ atendidas pela DEPI/MG. Os percentuais são bem mais elevados do que os de unidades policiais de porte, tais como Delegacia de Homicídios e Furtos e Roubos, reconhecidamente mais movimentadas, considerando-se o reduzido número de servidores policiais lotados na DEPI/ MG. A qualidade dos registros contidos nas 'comunicações de serviços’ teve sensível melhora. É possível enxergar, somente na leitura das 'comunicações de serviços', o chamado 'local de crime’, de forma clara e objetiva.

Quanto à saúde do servidor, ambas as turmas disseram que gozavam de boa e/ou ótima saúde. Contudo, ao se levantar a sintomatologia que eles apontaram com relativa freqüência, observase que sofrem grande desgaste psicológico ao ver que, mesmo executando os procedimentos relatados no mapa de instrução, o que lhes permite maior eficácia e eficiência, nada altera os rumos do positivismo legal, ou seja, tudo redunda na sansão de penas alternativas de liberdade na grande maioria dos casos registrados na DEPI/MG; no pagamento de cestas básicas à vítima; ou num simples ‘puxão de orelhas’ por parte do representante máximo da lei, o juiz, sob o suspeito ${ }^{7}$. Deste modo, necessitam de uma assistência mais próxima e efetiva dos setores responsáveis pela saúde dos funcionários.

Ao avaliar as atividades exercidas fora do ambiente de trabalho, notou-se que a turma 1 tinha mais tempo para as atividades de lazer (85\%) do que a turma 2 (30\%). Ambas ficavam com a família nas horas de folga, só que na turma 1 havia maior participação da família nas atividades sociais.

A quase totalidade dos que responderam ao questionário tem religião e disseram que ela os ajudava no enfrentamento das dificuldades cotidianas, de trabalho e pessoal. Da mesma forma, havia unanimidade quanto à projeção do futuro pois só um aluno pertencente à turma 2 não faz planos para o futuro.

\section{DISCUSSÃO}

A gestão do trabalho é cada vez mais relevante na área da psicologia do trabalho. Os aspectos emocionais e psicológicos**** estão intimamente ligados ao exercício profissional, à

\footnotetext{
**** De acordo com o disposto no plano nacional de segurança pública, os fenômenos da violência e da criminalidade são complexos e multidimensionais, ou seja, envolvem dimensões subjetivos e objetivas e são condicionados por fatores diversos, variáveis, cuja eficácia depende dos contextos históricos e das mediações culturais. Hoje, caso se promova uma auditoria externa das rotinas do trabalho policial nas delegacias, não há dúvida de que os resultados serão chocantes. A burocracia é tanta que, entre a denúncia, o registro da ocorrência e o início da investigação, demora-se, freqüentemente, um período absolutamente incompatível com a agilidade indispensável às investigações. Os policiais acabam impedidos de exercitar sua competência, tal o peso da burocracia labiríntica (p. 47).
} 
dinâmica organizacional e aos processos produtivos. Nessa inter-relação, surgem reflexos dentro da própria organização e na estrutura psicológica do trabalhador. Por isso, há necessidade também de uma abordagem sociológica no sentido de não desvincular o homem do social, uma vez que ele se constrói em relação e o trabalho é parte fundamental desta construção. A atividade do trabalho, a sua dinamicidade, é parte fundamental da compreensão do homem como um ser social, produtivo e portador de emoções que são vivenciadas e externadas em tudo o que faz ou produz.

Dentro deste contexto, nota-se que as duas turmas têm mais convergências que divergências nas respostas que deram ao questionário. Assim, elas divergem quanto à pluralidade do número de cargos representativos por turma, conforme mencionado no tópico 4 deste artigo. Há que se considerar que uma Unidade Policial ${ }^{8}$ compõe-se das seguintes carreiras policiais civis:

a) Delegado de Polícia ' Responsável pela administração geral da Unidade Policial. Obrigatoriamente possui nível de escolaridade superior, no campo do Direito.

b) Escrivão de Polícia - Responsável pela escrituração cartorária da Unidade Policial. Exige-se para ocupação deste posto de trabalho o nível médio de escolaridade, porém, sabe-se, empiricamente, que grande parte dos escrivãos de polícia já possuem nível superior de escolaridade, distribuídos aleatoriamente, nos campos do conhecimento do direito, psicologia, sociologia e história.

c) Detetive-Profissional da segurança pública responsável pela coleta das provas materiais da história 'criminis'. Assim como para o de Escrivão de Polícia, exige-se para este cargo o nível médio de escolaridade, porém há um grande número de detetives portadores do nível superior de escolaridade, particularmente no campo do Direito.

d) Funcionários administrativos - Não se encontram classificados dentre as carreiras policiais. São servidores públicos estaduais e/ ou municipais que auxiliam nos trabalhos de escrituração, serviços gerais e administrativos. Voluntários e estagiários.

e) Trata-se de mão-de-obra contratada para esse fim, que também auxilia nos trabalhos de escrituração, atendimento e encaminhamento social e psicológico.

O número de servidores policiais com 01 (um) ano de serviço na DEPI/MG foi maior na turma 2, demonstrando que houve alteração no quadro de servidores que prestam serviço nessa Unidade Policial e que, talvez, eles tenham sido designados de maternais consciente e consistente para uma atuação nessa Especializada.

Quanto aos pontos convergentes, merecem ser destacados os seguintes:

a) O horário de trabalho, tempo de serviço na Polícia Civil, percentual de policiais do sexo feminino e masculino e nível de escolaridade.

Há que se abrir um parêntese nesse tópico no que se refere ao horário de trabalho integral e aos trabalhos noturnos. A Lei Orgânica da Polícia Civil de Minas Gerais ${ }^{9}$ estabelece que o trabalho do policial é integral, sem especificar que se trata de 40 horas semanais. Essa não especialização permite uma leitura para as chefias autocráticas, muito encontradas na Polícia Civil, de que o trabalho policial deve ser realizado nas 24 horas do dia, ou seja, a qualquer momento um policial poderá ser chamado, mesmo na folga, para atuar como agente de segurança pública. Talvez isso explique os motivos pelos quais tenha sido notado um alto índice percentual de policiais que têm como lazer o "estar com a familia" 10 . Realmente, não há tempo de lazer, se considerarmos 24 horas de trabalho policial.

b) Mesmas queixas no que concerne ao baixo salário, fragilidade do sistema informatizado de informação e equipamentos de proteção individual, além do reduzido espaço físico da DEPI/MG para a realização das atividades a que ela se propõe.

$\operatorname{Monjardet}^{3}$ (p. 153) obteve esses mesmos resultados ao pesquisar os policiais franceses e norte-americanos. Essa autora observou que a intensidade dos conflitos sociais e dos problemas de ordem pública produz condições nas quais o poder recorre às forças policiais e é, nesse momento, que se manifestam as reivindicações materiais, de modo semelhante ao que vem ocorrendo com o Brasil atual. A Secretaria Nacional de Segurança Públic ${ }^{11-12}$, criada pelo Ministério da Justiça, tenta desde o ano de 2000 criar condições favoráveis de trabalho para as corporações policiais, inclusive sob o aspecto da integração das forças. Investe-se em projetos de capacitação e melhoria das 
condições materiais, sem antes mesmo existir uma diretriz com metas a curto, médio e longo prazo.

c) $\mathrm{O}$ estilo de gerenciamento, bem como a cobrança dos colegas e da chefia imediata, o fazer tudo com pressa e a constante interrupção do trabalho levam ao medo de errar e a vivenciarem situações estressantes, aliadas ao risco vivido diariamente nas várias situações de trabalho.

Bittner (2002, p. 2550-57) ${ }^{6}$ cita Bayley identificando nada menos do que vinte campos de atividade para as polícias da Europa Ocidental e norte-americana, cada um compreendendo suas proprias complexidades. Nessa lista, o policiamento investigativo e criminal aparece como sendo uma das atividades prioritárias entre as funções que a polícia exerce; mesmo assim, os policiais julgam mais importante capturar criminosos do que resolver brigas domésticas. Melhor dizendo, conforme o que foi apurado nos questionários, ser polícia é atuar de modo operacional e não administrativamente. Operacional significa estar no "front", na linha de fogo capturando "bandidos". O medo de errar está intimamente ligado à não preparação para a tomada de decisão adequada e ao desconhecimento de algumas regras que, na verdade, nem a chefia imediata, intermediária ou mesmo superior, sabe quais sejam. Mais uma vez citando Bittner ${ }^{6}$ (p. 332) há uma passagem muito interessante que serve para ilustrar essa argumentação:

"Os professores aprendem como educar, os padres como atender às necessidades espirituais, os assistentes sociais como auxiliar as pessoas com problemas. Todos eles devem utilizar os princípios que aprenderam, exercer julgamento ao colocá-los em uso e, por meio da prática, aumentar cada vez mais sua habilidade. Os policiais, entretanto, são treinados para seguir instruções, e isso é feito mesmo quando se sabe que deles vai ser exigida a realiza,cão de coisas para as quais não existem instruções. Mas essas atividades não ensinadas são mantidas com tal desdém, que não é considerada necessária nenhuma preparação para o engajamento nelas. (...) Consideremos o que acontece quando um policial, ao usar sua arma, mata ou fere alguém. Quase que invariavelmente, são realizados inquéritos para determinar se o policial envolvido pode ser civil ou criminalmente responsabilizado pelo ato. (...) e é necessário que se caminhe em direção ao reconhecimento de que tratar com um jovem

\begin{abstract}
insolente e desrespeitoso, resolver uma briga doméstica potencialmente grave, convencer um seqüestrador a libertar seu refém, prender um delinqüente, etc., cada uma de sua maneira, são atividades tão difíceis como ensinar álgebra a um aluno do primeiro colegial, lidar com um penitente religioso ou ajudar uma viúva com distúrbios mentais. Cada uma dessas atividades envolve o uso de conhecimento, habilidade e julgamento."
\end{abstract}

A DEPI/MG não poderia fugir a essa regra porque só há dois anos vem treinando os seus servidores para um atendimento especializado; porém, ainda se concentra no tópico resistência às mudanças e não implantação de rotinas de trabalho voltadas para o objetivo da DEPI/MG. Isso também impede o uso adequado de procedimentos padronizados e o correto arquivamento de dados que facilitariam a rápida obtenção de respostas às buscas das informações concernentes ao trabalho policial, mesmo com as falhas, apontadas pelos entrevistados, no sistema informatizado.

\section{CONCLUSÃO}

Os policiais da DEPI/MG acreditam, no contexto da análise das respostas ao questionário, que trabalham em equipe e, portanto, têm certa flexibilidade para mudar os processos de trabalho, o que, de certa forma, minimiza o risco do sofrimento psíquico. Porém, não se pode negar a necessidade de auxílio no campo dos recursos humanos para um melhor desempenho das suas atividades, tanto profissionais quanto pessoais. A energia vital que eles dispõem para fazerem planos para o futuro, aliado ao gostar de ser 'polícia’, são fatores imprescindíveis à otimização de ações que promovam o aprimoramento pessoal e profissional dos servidores da DEPI/MG.

Apesar de apresentarem pouco tempo de atuação nessa DEPI/MG, conforme constatado no levantamento sobre a saúde mental dos trabalhadores da Polícia Civil, 80\% deles já atuou como policial em outras Unidades Policiais, portanto, já trazem uma bagagem sobre o trabalho de polícia. O conhecimento obtido na Academia de Polícia Civil ao ingressarem na carreira policial, na maioria dos casos, representa $30 \%$ das aplicações no serviço rotineiro e cotidiano, os $70 \%$ restante foi obtido de modo empírico e, em muitos casos, de forma dolorosa, como perda de parceiros, perda da família, e até com perdas da própria vida. É essa nova bagagem, altamente pautada no empírico, que transforma o policial num ser desconfiado e temeroso em tomar decisões que possam implicar a perda do seu pseudo poder. 
Não que o tipo de conhecimento enfatizado na escola de polícia, fixado na multidisciplinaridade e no academicismo, esteja incorreto. Porém, nos dois casos, falta-lhes coerência. O equilíbrio entre o empírico e o teórico forneceria a liga nesse processo, transformando esse sujeito em cidadão do mundo, capaz de interagir e de se posicionar como ser pensante, tão importante quanto os de outras profissões e tão capaz quanto os demais seres humanos.

Certo é que o policial aprende durante o período que se encontra na 'lida' do dia-adia após o período que passa pela Escola de Polícia, em Minas Gerais, a Academia de Polícia e o tempo legal de estágio (03 anos); que o verdadeiro trabalho de polícia concentra-se na captura de criminosos e, portanto, de nada resolve a burocracia da papelada. Observa-se, como resultante dos levantamentos, que o policial é alguém dotado de uma memória capaz de registrar todos os fatos e eventos de risco vinculados à profissão, sem jamais esquecer-se do que Ihe interessa. Deste modo, há o registro do que ele deduz que seja importante; pelo menos, é o que ocorria na DEPI/ MG. Atualmente, tenta-se endireitar essa rota histórica na DEPI/MG por meio do uso de procedimentos de rotina que lhes permite atuar como policiais de fato, de modo científico, aliando-se à prática do fazer polícia. Faz-se necessário aqui, mais uma vez apelar, como recurso ilustrativo e explicativo, para os dizeres contidos no plano nacional de segurança pública ao delinear a típica delegacia brasileira. Parece-nos a expressão mais eloqüente dos aspectos improdutivos e paralisantes de nossa herança cultural: para que um papel volte a ser um papel dotado de valor, isto é, converta-se em documento, é preciso submetê-lo ao itinerário de vários endossos e revalidações cartoriais, envolvendo turnos diversos e mobilizando distintos profissionais. Isso tudo transcorre em ambientes fisicamente degradados, insalubres e hostis. Os policiais e o público sentem-se desrespeitados pelo cenário decadente. Nada mais propício à instauração dos ciclos viciosos de todo tipo. Nada menos estimulante para um bom desempenho policial. Aí reside a baixa auto-estima, comprovada nos levantamentos de dados sobre as expectativas dos policiais tanto dos dados obtidos pelo setor de psicologia da Academia de Polícia Civil, desde os idos anos de 1979, quanto pelos registros contidos na obra de
Monjardet ${ }^{3}$, porque ali não se encontram respostas para questionamentos, tais como: É possível mensurar esse tipo de conhecimento e competência? Há que se ter vocação para essa profissão? Quem seleciona esse pessoal? É necessário ter um dom especial para a 'coisa'?

É importante ressaltar que o ensino policial formal possui dois pilares: o real (prática) e o que chamaremos aqui de virtual (acadêmico), um distando consideravelmente do outro. A doutrina policial civil direciona-se pelo positivismo das leis brasileiras, principalmente pelos códigos penal e processual penal. Quanto ao perfil profissiográfico, traçado pelo setor de psicologia da Academia de Polícia Civil, que norteia o ensino policial civil, o termo vocação aparece com freqüência, mesmo sabendo-se que esse vocábulo de origem latina significa predestinação, talento, portanto, um chamado que pode bem ser do 'além'.

Em Minas Gerais, três são os cursos obrigatórios oferecidos pela Academia de Polícia Civil. O primeiro, o de ingresso na carreira, denomina-se Formação Policial; o segundo, de Aperfeiçoamento Policial. Em geral, a demanda para esse curso ocorre após os três primeiros anos de profissão. O último, chamado de Chefia Policial, tem o foco na gestão profissional. E todos pontuam a vocação como fator preponderante para que alguém consiga se tornar polícia. Por isso a grande distância que existe entre o acadêmico e o prático.

Desta maneira, o policial, não consegue sair do 'estar' Indivíduo e transformar-se em 'ser' Sujeito, fechando-se em seu universo, e, portando, sendo incompreendido, adorando as suas próprias leis e seus próprios códigos. O contato com o mundo, se assim pode-se dizer, faz com que o policial se torne, realmente, um ser diferente dos demais, que necessita de acompanhamento biogeronto-psicossocial e de diretrizes que possam nortear o seu caminho de maneira eficaz, eficiente e coerente com a realidade. A importância em mostrar para esse profissional de segurança pública que, na grande maioria dos casos, ao ingressar na profissão, acredita estar atendendo a um chamado, de que ele é um ser humano como outro qualquer, de carne e osso, portanto sujeito ao envelhecimento, fez com que passássemos a acreditar na eficácia da orientação gerontológica desde o seu ingresso na carreira policial civil, em Minas Gerais. 


\begin{abstract}
The Specialized Police Station of Protection for lhe Elder - DEPI/MG - was created in 1997 with lhe purpose of taking care of lhe elder victim of mistreatment. In Brazil, there are only three other Police Units that, like lhe DEPI/MG, focus on lhe elder as victims: one is located in São Paulo, another one in Rio de Janeiro, and lhe third one in Rio Grande do Sul. However, their objectives are different from those of lhe Police Station of Belo Horizonte, capital of lhe State of Minas Gerais. This one is a specialized police unit, due to its character of providing assistance for a specific public - the elder. Unfortunately, although in the vanguard - it was the second unit of this nature created in Brazil -, the policemen assigned to act in this Police Station have not attended any type of qualification course, and have not received any kind of training. Since the middle of 2000, a data collection work was initiated in this DEPI/MG, aiming to analyze the internal dynamics and to indicate, in the future, possible organizational changes and interventions. Due to this, the team of researchers, concerned about the external and internal publics, demanded the mental health survey of the workers of the civil police in the DEPI/MG. This article presents the outcomes of this data collection, which was carried out, at first, in an initial period of internal changes in the DEPI/MG and, one year later, in a phase of transational management.
\end{abstract}

Key words: Mental health. Civil Police. Elder. Elder Abuse.

\section{REFERÊNCIAS}

1 Vanagunas S. Planejamento dos serviços policias urbanos. In: Greene JR, organizador. Administração do trabalho policial. São Paulo: Edusp; 2002. cap. 2, p. 43-57.

2 Ministério da Justiça. Secretária Nacional de Segurança Pública. Plano Nacional de Segurança Pública. Brasília (DF); 2001.

3 Monjardet D. O que faz a policia. São Paulo: Edusp; 2002.

4 Menke BA, White MF, Carey WL. Profissionalização da polícia: em busca de excelência ou de poder politico? In: Greene JR, organizador. Administração do trabalho policial. São Paulo: Edusp; 2002. cap. 2, p.85-117.

5 Antunes MEL. Questionário: levantamento sobre a saúde dos trabalhadores da polícia civil. Belo Horizonte: FAFICH/UFMG; 2002 (manusc.)

6 Bittner E. Aspectos do trabalho policial. São Paulo: Edusp; 2002.

7 Chaves PGS, Costa PL. A vivência afetiva e a violência doméstica contra o idoso. Brasília: MJ/ SENASP; 2003.
8 Minas Gerais. Resolução 6.264, 3 dez. 1997. Cria a Delegacia Especializada de Proteção ao Idoso. Belo Horizonte: Imprensa Oficial; 1997.

9 Minas Gerais. Lei orgânica da Polícia Civil: lei n. 5.406 de 16/12/69. Belo Horizonte: ACADEPOL; 1989.

10 Oliveira RdCM. A configuração da QVT no contexto de trabalho dos detetives da polícia civil metropolitana de Belo Horizonte [dissertação]. Belo Horizonte (MG): Faculdade de Direito da UFMG; 2001.

11 Ministério da Justiça. Secretária Nacional de Segurança Pública. Projeto Segurança Pública para o Brasil. São Paulo: Instituto Cidadania; 2002.

12. Ministério da Justiça. Secretária Nacional de Segurança Pública. Projeto Segurança Pública para o Brasil. Brasília (DF); 2003.

Recebido em 14/01/2004

Modificado em 18/03/2004

Aprovado em 25/03/2004 